\title{
CT 造影製剂特性が造影効果に及ぼす影響
}

\author{
寺澤和晶 ${ }^{1,2)}$ ・八町 淳 ${ }^{1)}$ ・奥田逸子 ${ }^{2,3)}$ \\ 1 ) 長野赤十字病院中央放射線部 \\ 2)鈴鹿医療科学大学大学院医療科学研究科 \\ 3) 国際医療福祉大学三田病院放射線診断センター
}

Code No. 251

\section{緒 言}

画素值 $[\mathrm{CT}$ 值 : hounsfield unit (HU)]のダイナミッ クレンジ(dynamic range)が広い CT 装置ではある が，体内の軟部組織は狭い吸収值領域に密集して分 布しており，現在の装置では何らかの薬剤負荷を与 えなければ血液の循環動態を画像化することは不可 能である。この欠点を補うためヨード造影剤を使用す るが, multi-slice CT (MSCT)の急速な開発によって, 撮像時間 (s)の短縮, thin-sliceによる広範囲の撮影が 可能になったため, CT 造影検査において, 高い CT 值を得るために時間濃度曲線(time-density curve; TDC $)^{1,2)}$ のピークを高く，ピーク幅を狭くするような 急速静注が行われるようになってきた。この手法は, 装置性能に組み合わせ，ヨード使用量 $(\mathrm{mgI})$ の低減を 目的に応用する技術として発展的な側面をもってい る。しかしながら，臟器を十分に濃染させる質的診 断検査に扮いては, 最適なヨード使用量, 撮像タイ ミングに関して装置間に性能差があっても大きく変化 しない普遍的な側面ももつ ${ }^{3)}$.

CT 画像は, ウィンドウ幅(window width; WW),

\section{Effects of Computed Tomography Contrast Medium Factors on Contrast Enhancement}

\author{
Kazuaki Terasawa, ${ }^{1,2)}$ Atsushi Hatcho,") and Itsuko Okuda ${ }^{2,3)}$ \\ 1) Central Radiology Department, Nagano Red Cross Hospital \\ 2) Suzuka University of Medical Science, Graduate School of Health Science \\ 3) Department of Diagnostic Radiology, International University of Health and Welfare, Mita \\ Hospital \\ Received June 28,2011; Revision accepted September 27, 2011; Code No. 251
}

\section{Summary}

The various nonionic iodinated contrast media used in contrast computed tomography (CT) studies differ in terms of their composition, characteristics, and iodine concentration $(\mathrm{mgI} / \mathrm{ml})$, as well as the volume injected ( $\mathrm{ml}$ ). Compared with ionic iodinated contrast media, nonionic iodinated contrast media are lowosmolar agents, with different agents having different osmotic pressures. Using a custom-made phantom incorporating a semipermeable membrane, the osmotic flow rate (HU/s) could easily be measured based on the observed increase in CT numbers, and the relationship between the osmotic pressure and the osmotic flow rate could be obtained $\left(r^{2}=0.84\right)$. In addition, taking the effects of patient size into consideration, the levels of contrast enhancement in the abdominal aorta (AA) and inferior vena cava (IVC) were compared among four types of CT contrast medium. The results showed differences in contrast enhancement in the IVC during the equilibrium phase depending on the type of contrast medium used. It was found that the factors responsible for the differences observed in enhancement in the IVC were the osmotic flow rate and the volume of the blood flow pathways in the circulatory system. It is therefore considered that the reproducibility of contrast enhancement is likely to be reduced in the examination of parenchymal organs, in which scanning must be performed during the equilibrium phase, even if the amount of iodine injected per unit body weight $(\mathrm{mgI} / \mathrm{kg})$ is maintained at a specified level.

Key words: contrast media, contrast enhancement, time density curve (TDC), osmotic pressure, equilibrium phase

別刷資料請求先：干 380-8582 長野市若里 5-22-1 


\section{Scout View}
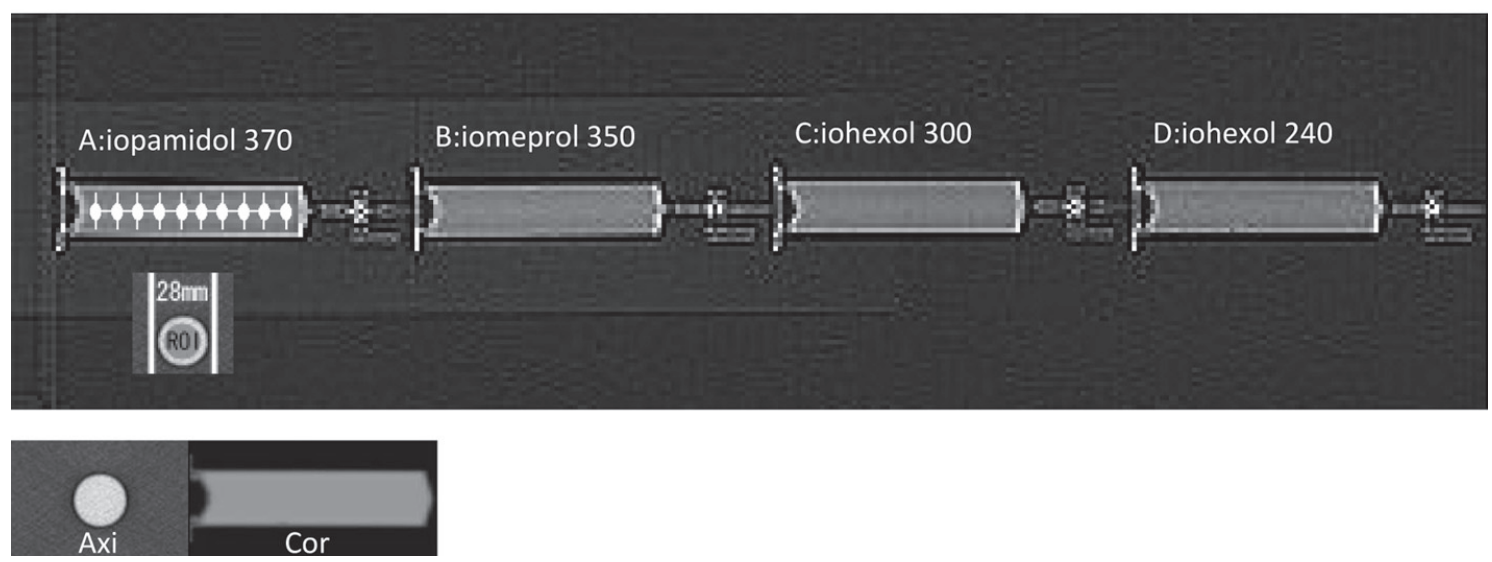

Fig. 1 Phantom with the iodine dilution factor maintained at a specified level in the each contrast media.

WW の中心になるウィンドウ值 (window level; WL)に よりウィンドウ設定され，濃度階調によって目に見え るコントラスト差となって表示される。 日常, CT 画 像の読影の際に造影効果が一定でない場合, その都 度，WWやWLを詳細に設定する必要性が生じる。 このため, 被検者間の比較や経時的変化の観察など において再現性が重要になってくる。そのうえ, 臓器 および病変によって TDC 形状が変化する濃染強度パ ターン4)もあるため, ヨード使用量を規格化する必要 性がある。また，造影剤投与は，被ばく同様に身体 的負担であり，適正なヨード使用量で有益なデータを 得るのみならず，リスクを抑えることが求められる。 したがって，検査部位に応じて目標の CT 值を定め, 安定した造影効果, 高い再現性を得ることが必要に なる。一方で, 撮像線量, 画像表示方法が規定され なければ，投与するヨード量を規格化することも難し く, 統合的に CT 検査を標準化することに関しては現 在模索の範囲といわざるを得ない面もある.

そのなかで，単位体重当たりのヨード使用量 $(\mathrm{mgI} / \mathrm{kg})$ を一定にすることで，再現性の向上がはかれること5) が一般的になってきた。ただ，最近では線質硬化に よる X 線実効エネルギーの変化によるヨードの CT 值変動6,7)などが報告され，補正要因として研究され 始めた。このため, 被検者間の造影効果を比較する 場合，体格を考慮する必要がある。さらに，CT 造影 検査用にヨード含有の検査薬として販売されている 非イオン性ヨード造影剤(以下，造影剤)は，製剤間 の差別化をはかるため組成・性状やヨード含有量 $(\mathrm{mgI} / \mathrm{ml})$, 容量 $(\mathrm{ml})$ が異なっている. イオン性に比 べ低浸透圧性になっていることもその一つであるが, 各製剤における浸透圧の違いはさまざまである。この ため，ヨード使用量が同一でも，製剤間に差異が認
められる可能性がある，当施設でも，検査目的によっ て体重 $(\mathrm{kg})$ を基準に用法・ヨード使用量を使い分けて いるため，4 種類の製剤を使用している。しかし，浸 透圧および体格差によるエネルギーの影響を踏ま え，製刜間における造影効果の定量を行った経験は なかった。同じように，そのような報告も狭義にな い. そこで，今回， CT 造影剤特性が造影効果に及ほ す影響を腹部における大動脈および大静脈において 比較し検討を行ったので報告する。

\section{1. 使用機器および製㓮・材料}

CT 装置は，東芝メディカルシステムズ社製 Aquilion64, 自動注入器は，根本杏林堂社製 Dual Shot-GX を使用した。造影剤はヨード含有量が異な る A : iopamidol 370, B : iomeprol 350, C : iohexol 300, D: iohexol 240 の 4 種類で, 加温器にて $37^{\circ} \mathrm{C} に$ 加温した。 なお, 臨床において穿刺用の留置針はテル モ社製 $20 \mathrm{G}$ (内径: $0.8 \mathrm{~mm}$, カテーテル長: $32 \mathrm{~mm}$ ) を用い, トップ社製インジェクタ用エックステンション チューブ(耐圧性能：1.47 MPa) $100 \mathrm{~cm}$ にて接続した。

\section{2. 方 法}

2-1 ファントムによる基礎的検討

\section{2-1-1 ヨード使用量と上昇 CT 值}

各製剤 $(\mathrm{A} \sim \mathrm{D})$ において総ヨード使用量を一定にし て (1), (2)のCT 值を測定した。撮像条件は管電圧 $120 \mathrm{kV}$, 管電流 $150 \mathrm{~mA}$, 管球回転速度 0.5 秒で, ス ライス厚は $2 \mathrm{~mm}$ とした。また, 有効視野 (field of view; FOV) $240 \mathrm{~mm}$ で, calibration data は large(L)に て収集した。

(1)循環濃度測定ファントム ${ }^{8)}$ における TDCの変化. 循環水量は 5.81 で循環量 $5.4 \mathrm{l} / \mathrm{min}$, ヨード使用量は 

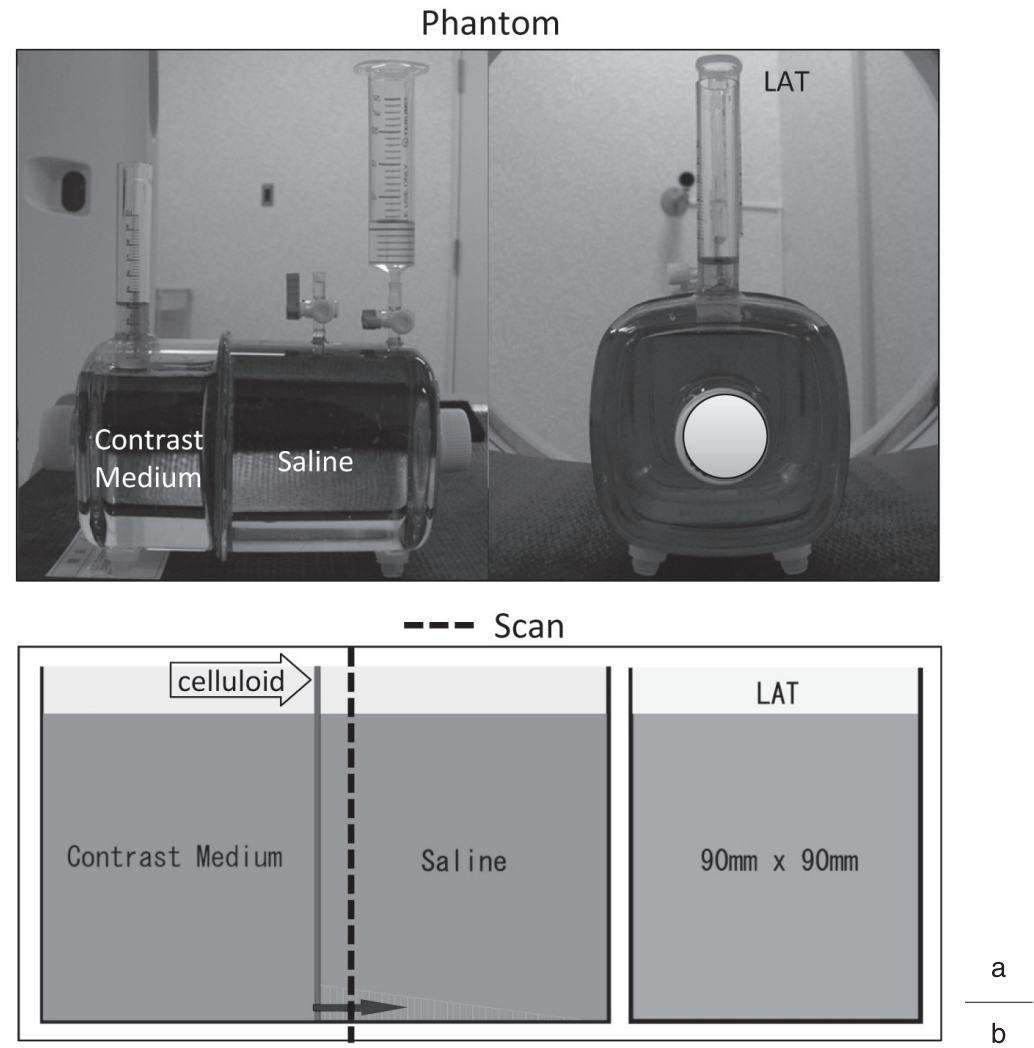

Fig. 2 The custom-made phantom incorporating a semipermeable membrane.

Right

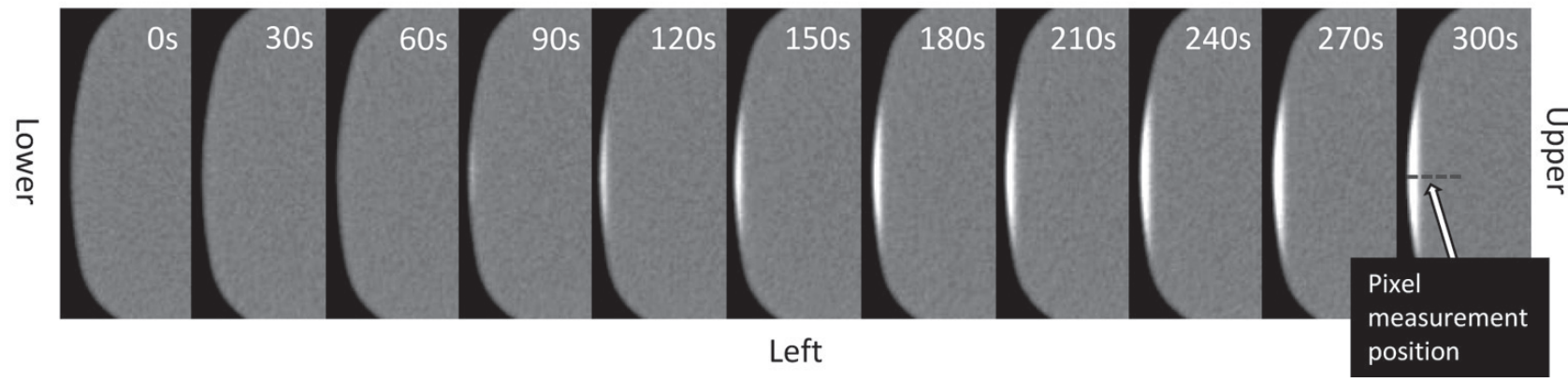

Fig. 3 CT image every elapsed time.

$34 \mathrm{gI}$ で 35 秒注入.

(2)円筒ファントム $(\phi 28 \mathrm{~mm})$ にヨード濃度 $(\mathrm{mgI} / \mathrm{ml})$ を 一定にした希釈溶液を密封。希釈には生理食塩水(以 下，生食)を使用. Fig. 1のようにすべてガントリ中心 になるよう直列に配置し， $5 \mathrm{~mm}$ 間隔で 10 点( $\phi 80 \%$ の領域を計測).

\section{2-1-2 浸透圧の影響}

セロファン(セルロース)の半透膜シートを仕切りに した Fig. 2(a)の自作ファントムを用い, 造影剂と生食 間に起こる浸透現象を利用して CT 值変化による簡 易的なヨード通過速度 $(\mathrm{HU} / \mathrm{s})$ を観測することとした。
測定は半透膜面を中心にして造影剤側から $5 \mathrm{~mm}$ 外 側を 30 秒間隔で撮像し，ピクセル值によるCT 值を 求めた. Fig. 2(b) はその模式四である。計測位置お よび時系列における計測断面を Fig. 3 に示す. A〜D 製剤のヨード濃度は，A から順に370，350，300， $240 \mathrm{mgI} / \mathrm{ml}$ の原液である。実験はすべての材料を室 温 $27^{\circ} \mathrm{C}$ の室内に 24 時間保管し，同室温にて行った.

\section{2-2 対 象}

腹部造影検査において動脈相と平衡相を有する 130 症例であった。 その内訳を Table 1 に表記した。 
Table 1 Data of the number of patients in each group and age and the weight (Mean \pm SD)

\begin{tabular}{cccll}
\hline \hline Group & Contrast medium & $\mathrm{n}$ & Age $(\mathrm{yr})$ & Weight $(\mathrm{Kg})$ \\
\hline A & Iopamidol 370 & 31 & $67.2 \pm 12^{*}$ & $53.2 \pm 7.5^{* *}$ \\
B & lomeprol 350 & 28 & $69.6 \pm 8.4^{*}$ & $52.9 \pm 7^{* *}$ \\
C & Iohexol 300 & 36 & $64.7 \pm 12.6^{*}$ & $51.7 \pm 6.1^{* *}$ \\
D & lohexol 240 & 35 & $68.4 \pm 11.2^{*}$ & $49.9 \pm 2^{* *}$ \\
\hline
\end{tabular}

${ }^{*} \mathrm{p}=0.34, \quad *{ }^{*} \mathrm{p}=0.11$

そして、A〜Dの造影剤を用いた被検者の体重につ いては，体格がほぼ一定になるように高体重および 低体重の対象を除外したデー夕を取得し，グループ 分けをした(グループ A， B， C， D)．グループ間の体 重㧍よび年齢の差は有意水準 0.05 で一元配置分散分 析法 (One-way factorial analysis of variance; ANOVA) を使って検定した。

なお，本研究は以上の症例を非ランダム化して比 較するとともに当施設における倫理委員会の承認を 受けている。ちなみに，製剤の規格上，一部対象は 診断群分類包括評価 (diagnosis procedure combination; DPC)における場合にて応じ適切な被検者負担と している。 また，造影剤による副作用の報告もない．

\section{2-3 撮像方法および造影剂注入方法}

臨床に打ける撮像条件は，管電圧 $120 \mathrm{kV}$ ， スライ 久厚 $0.5 \mathrm{~mm}$ で, 自動露出機構 (auto exposure control; $\mathrm{AEC})$ を用い, 単純(plain; P)の画像ノイズ (standard deviation; SD) は 13, 造影 (contrast enhancement; CE)は 10 に設定した. Pitch factor (PF)は 0.83 で管 球回転速度は 0.6 秒とした。また、ヨード使用量は $450 \mathrm{mgI} / \mathrm{kg}$ とし, 可変定数 0.3 にて 35 秒一定で可変 注入した ${ }^{9)}$. 撮像タイミングは, 当施設の検査プロト コルにおける撮像開始時間である動脈相が 30 秒で平 衡相が 180 秒である9.

\section{2-4 撮像部位 (評価部位)および評価法}

評価部位は, 腹部大動脈 (abdominal aorta; AA) 扮 よび下大静脈 (inferior vena cava; IVC) とした，測定 は 3 点(心窩部，腎門部，分岐部)とし(Fig. 4)，その 平均值を求めた。 なお, 計測する関心領域(region of interest; ROI)のサイズは血管径の $\phi 80 \%$ 程度とした。 評価は, CEから P を減じた上昇值[enhancement unit; EU(HU)] 求め, Dunn 法による多重比較検定 を用い，有意水準 0.05 にて検定を行う方法とした.

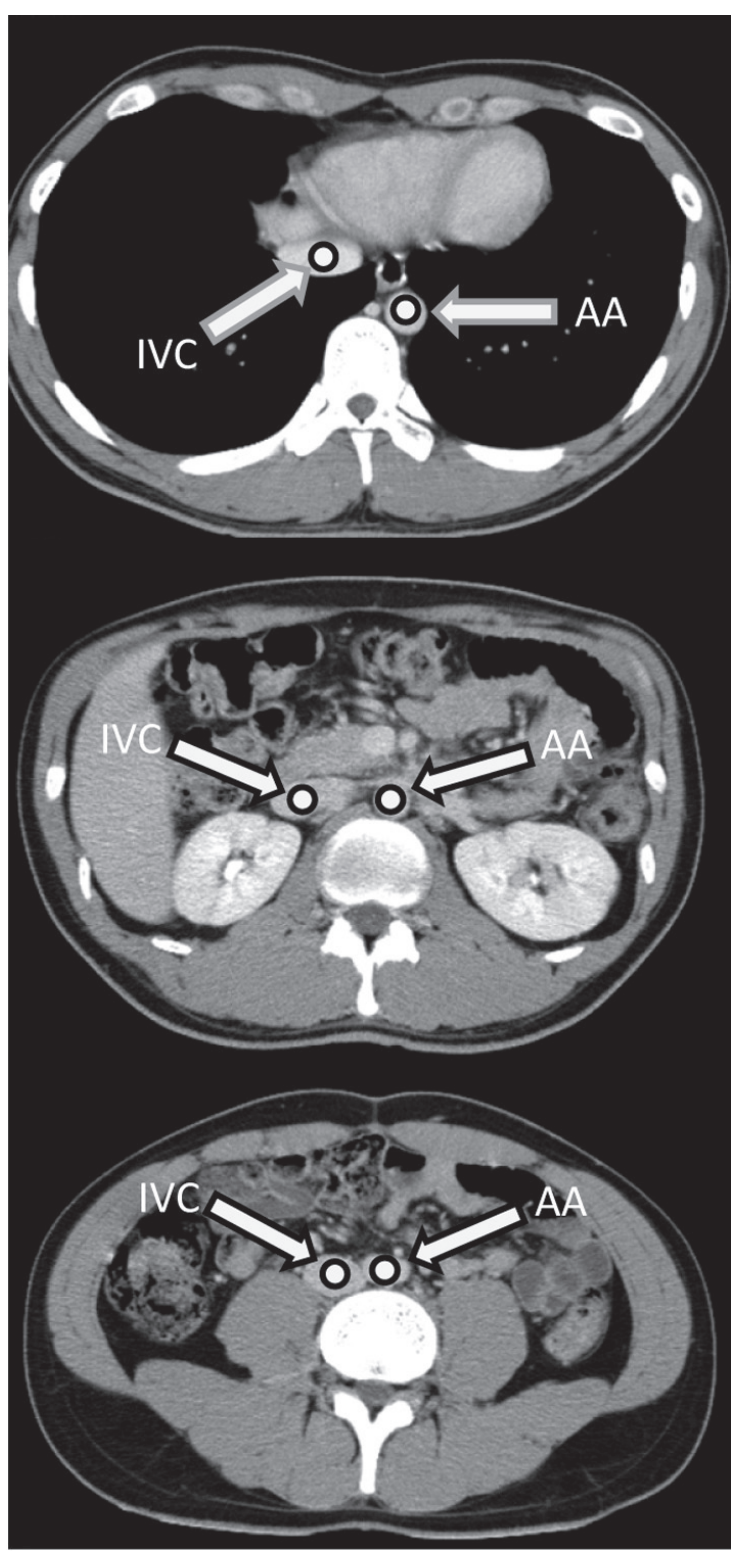

Fig. 4 Measurement position of CT numbers in the abdominal aorta (AA) and inferior vena cava (IVC).

\section{3. 結 果}

3-1 ファントムによるTDC および浸透現象によ る上昇 CT 值速度 $(\mathrm{HU} / \mathrm{s})$

Fig. 5 に各製剤の TDC を示す。ヨード使用量が一 定の場合, 動脈系抢よび静脈系の上昇 CT 值に大き な変化はなかった，また，円筒ファントムでも，Fig. 6 のようにヨード希釈量を一定にした溶液は製剂によら ず CT 值は一定になった $(\mathrm{p}=0.25)$.

Fig. 7 に各製剤の浸透現象による CT 值変化となる 経過時間(s) と最大 CT 值の関係を示す. Fig. 8 は浸 透現象による上昇 $\mathrm{CT}$ 值速度 $(\mathrm{HU} / \mathrm{s})$ ， いわゆる傾き の変化であるが，ピークに達するまでの傾きが異なっ た。 その関係は最大で D : $1.89<\mathrm{B}: 2.13<\mathrm{C}: 2.52<$ $\mathrm{A}: 2.53(\mathrm{HU} / \mathrm{s})$ であった. 


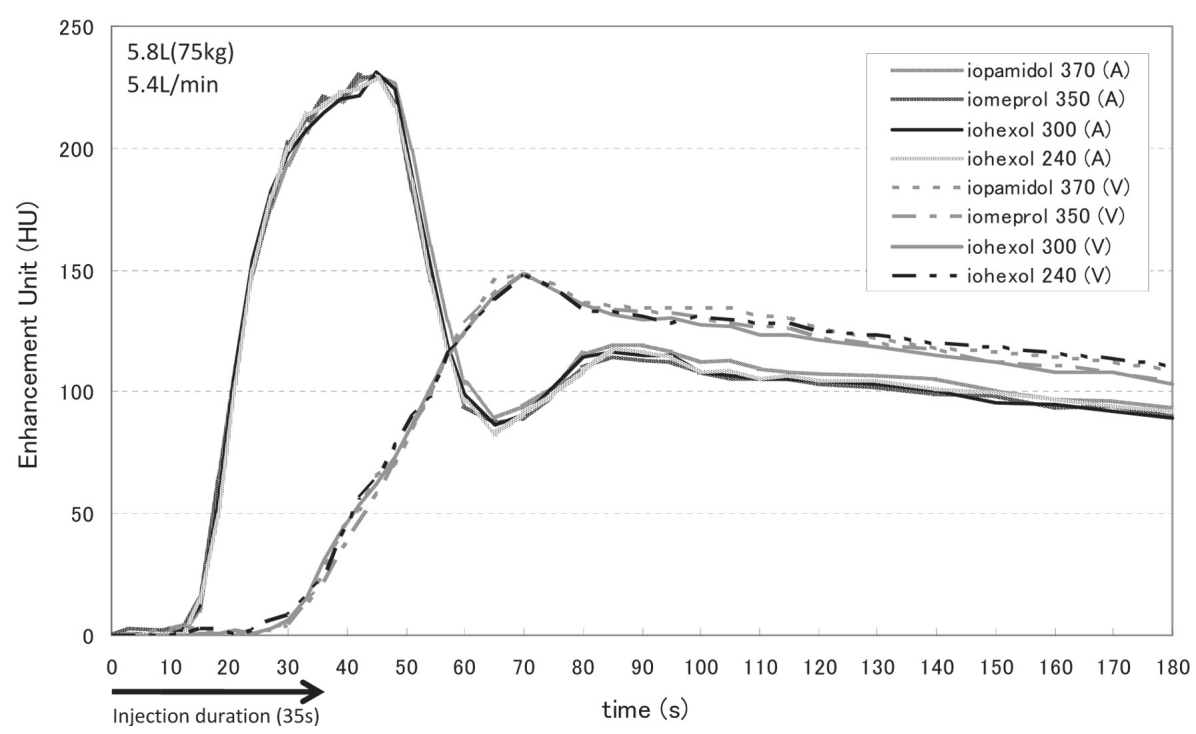

Fig. 5 Relationship between the increase in CT numbers in a TDC phantom and the type of contrast medium (with the amount of iodine injected maintained at a specified level).

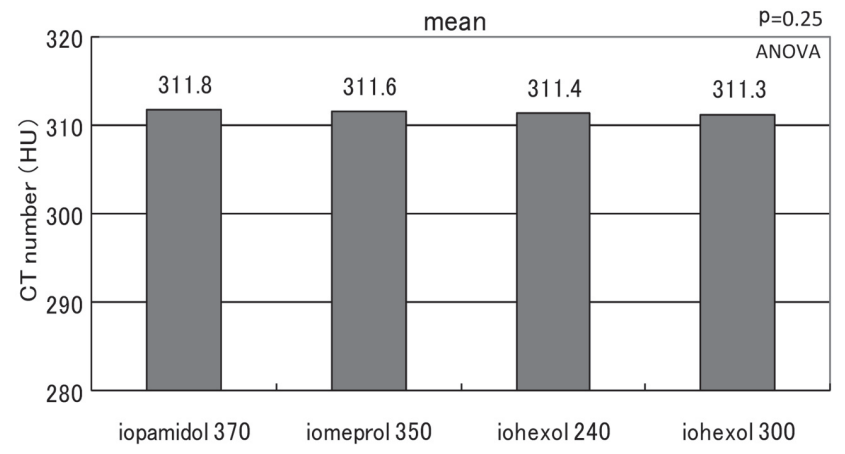

Fig. 6 CT numbers (air) in the phantom with the iodine dilution factor maintained at a specified level.

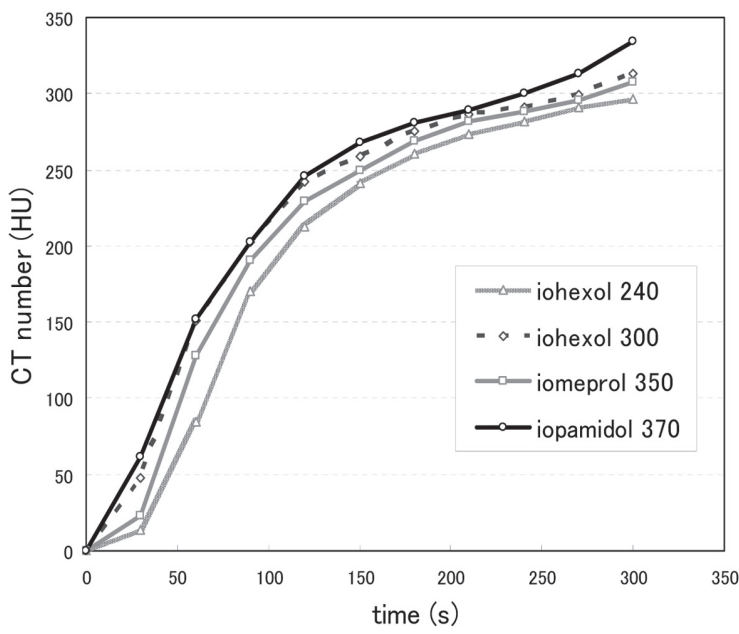

Fig. 7 Measurements of each contrast media in a Phantom (incorporating a semipermeable membrane).

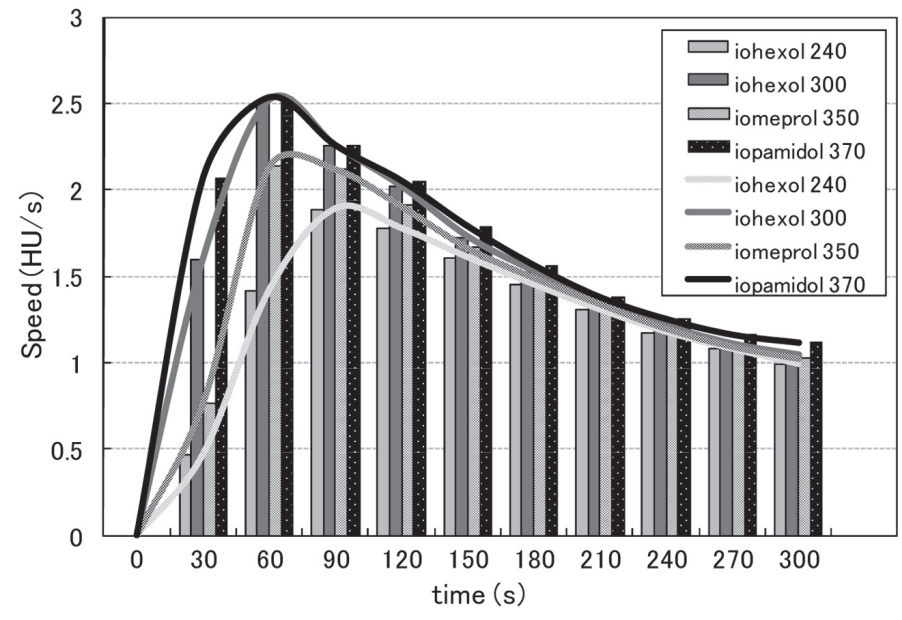

Fig. 8 Relations of elapsed time (s) and the osmotic flow rate $(\mathrm{HU} / \mathrm{s})$. 
Table 2 Increase in CT numbers (HU) of every group in each measurement position (Mean \pm SD)

Dunn

\begin{tabular}{|c|c|c|c|c|}
\hline \multirow{2}{*}{$\begin{array}{c}\text { Measurement } \\
\text { point }\end{array}$} & Group A & Group B & Group C & Group D \\
\hline & $\begin{array}{c}\text { Iopamidol } 370 \\
(\mathrm{HU})\end{array}$ & $\begin{array}{c}\text { lomeprol } 350 \\
(\mathrm{HU})\end{array}$ & $\begin{array}{c}\text { Iohexol } 300 \\
(\mathrm{HU})\end{array}$ & $\begin{array}{c}\text { lohexol } 240 \\
(\mathrm{HU})\end{array}$ \\
\hline $\mathrm{AA}(30 \mathrm{~s})$ & $247.2 \pm 38.6$ & $242.9 \pm 50$ & $245.3 \pm 46.7$ & $231.7 \pm 30.5$ \\
\hline $\mathrm{AA}(180 \mathrm{~s})$ & $73 \pm 12.2$ & $75.6 \pm 8.8$ & $73.5 \pm 11.9$ & $74.5 \pm 13.5$ \\
\hline IVC (180 s) & $63.3 \pm 8.5$ & $69.5 \pm 7.4 *$ & $65.3 \pm 7.5$ & $68.9 \pm 9.2 *$ \\
\hline
\end{tabular}

$* \mathrm{p}<0.05$ vs iopamidol 370
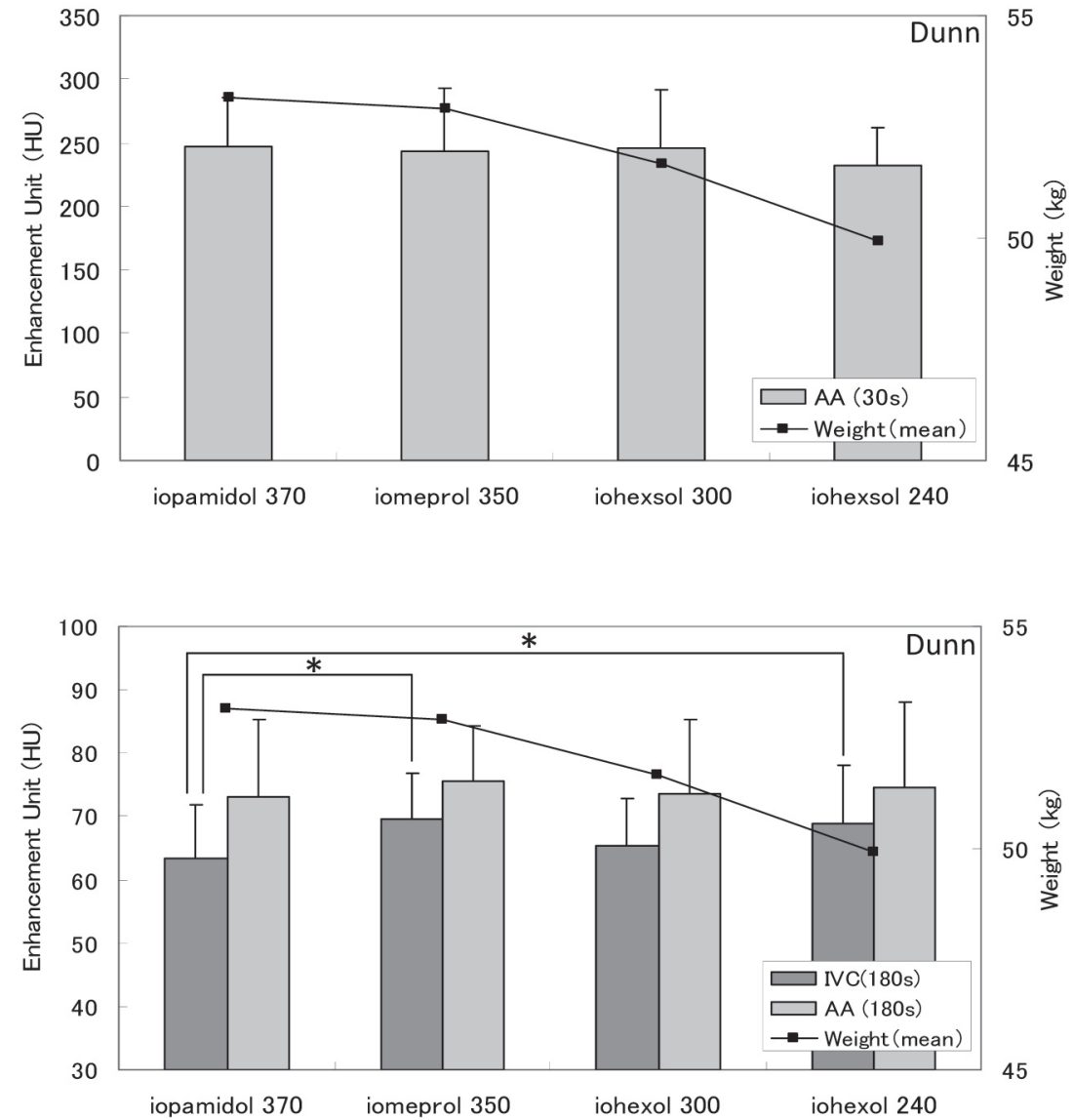

Fig. 9 Increase in CT numbers $(\mathrm{HU})$ of the abdominal aorta (AA) in the arterial phase.

Fig. 10 Increase in CT numbers (HU) of the abdominal aorta (AA) and inferior vena cava (IVC) in the equilibrium phase.

3-2 各グループにおける被検者データ

体重 $(\mathrm{p}=0.11)$ および年齢 $(\mathrm{p}=0.34)$ に有意な差はな かった。ただ，性差10)について詳細な検討は行って いない. Table 2 に評価部位の全データを表記した。 また，Fig. 9，10 は各評価部位のデータである。臨床 データにおいては動脈相・平衡相の AA において差異 はないものの，IVCにおいてグループAと $\mathrm{B}$ ，グ ループ A と D に有意な差があった $(\mathrm{p}<0.05)$.

\section{4. 考 察}

4-1 生体における影響

Fig. 5 から循環する環境において各製剤の TDC は
ほぼ同様になった。 また，Fig. 6 から円筒ファントム においても希釈造影剤の CT 值に違いは見られな かった。よって，ヨード使用量が一定の場合，状態に かかわらずファントムにおいては，製剤の組成・性状 の影響は受けないことが検証できた。これは，ファン トムが樹脂で閉鎖された環境であるためと考えられ る。したがって，被検者の体格がほぼ一定の場合に おいて造影効果に差異が生じたとすると，心機能な ど生体因子 ${ }^{11)}$ のほかに，製剤の性状が影響すると仮 定できる.

造影剤の性状で大きな因子に浸透圧と粘稠度があ る. Gallotti ら ${ }^{12)}$ は正確な浸透圧 $\left(\mathrm{Osmol} / \mathrm{kg} \cdot \mathrm{H}_{2} \mathrm{O}\right)$ や粘 
稠度 $(\mathrm{mPa} \cdot \mathrm{s})$ を求めている。これによると, 製剤 $\mathrm{A}$ 一 Dの浸透圧は D : $0.52<\mathrm{B}: 0.62<\mathrm{C}: 0.68<\mathrm{A}: 0.8$ $\left(\mathrm{Osmol} / \mathrm{kg} \cdot \mathrm{H}_{2} \mathrm{O}\right.$ at $\left.37^{\circ} \mathrm{C}\right)$ とされている. Fig. 11 は, そ れを改変引用したファントム実験による上昇 CT 值速 度の最大值と浸透圧の関係である。このことから, 浸 透圧值とピークまでの傾きに密接な関係があることが わかる $\left(\mathrm{r}^{2}=0.84\right)$ 。 また, Fig. 8 から，60～90 秒程度 の時間で傾きが最大となることから, ファーストパス となる肺(小)循環系において浸透圧の影響は相対的 に小さくなると推察され, その影響は動脈相以降に 生じてくると考えられる.

また，各製剤の粘稠度は， D : $3.3<\mathrm{C}: 6.0<\mathrm{B}: 7.5$ $<\mathrm{A}: 9.4\left(\mathrm{mPa} \cdot \mathrm{s}\right.$ at $\left.37^{\circ} \mathrm{C}\right)$ とされている ${ }^{12)}$. 今回, 粘稠 度の検討は行っていないが, 循環ファントムではない ものの実験上, 造影剤のファーストパスにおいて最大 $\mathrm{CT}$ 值の変化は伴わないが, 粘稠度が高いほど造影 剂の滞在時間が若干長くなり，TDCの形状に影響を 与えるとの報告 ${ }^{13)}$ がある。これによると, 粘稠度は平 衡相に影響しないと判断できる。 また，3-1 が示すよ うに, ヨード使用量が一定の場合, 製剤間に差がな いことから, 粘稠度は平衡相に影響を与える因子で はないと推察できる。そもそも, 粘稠度の影響は通過 抵抗 ${ }^{14)}$ が主となる。したがって, 粘稠度は温度によっ て変化するため適切な加温と温度管理が重要と考え る、ただ，自動注入器を用い注入の時間を管理する ことが可能であるため, 留置針およびシリンジの耐圧 性能の確保によってほぼ解消されると考える.

これらから，生体はヨード使用量を一定にしても， 浸透圧および粘稠度の影響を生じるといえるが，特に 浸透圧の違う造影剤を用いた場合，平衡相において その影響を大きく受ける可能性があると考えられた。

\section{4-2 各時相における大動脈と大静脈の造影効果}

問題となるのが動脈相における造影効果のバラつ きである。動脈相は，単位体重あたりヨード量および 注入時間を一定としても TDC が一定とならない場合 がある。これは心拍出量 [cardiac output (1/min);CO] の影響を受け, TDC の造影剤検出時間 (s), 最大 CT 值到達時間 (s)に個体差があるためである ${ }^{15)}$ 。このた め, 撮像夕イミングを固定した検査プロトコルでは造 影効果に差異が生ずることがある。しかし，今回， Fig. 9 に示すように動脈相におけるグループ間の造影 効果に有意差を認めないことから，特異な被検者の デー夕はないと判断した。また，体格の影響も体重お よび年齢に有意な差がないことから同様に判断した。 ここで, 動脈相の AA に造影効果に CO 以外の因子 は影響しているかということになるが，4-1 より浸透 圧の影響は平衡相になるため，その影響は小さいと

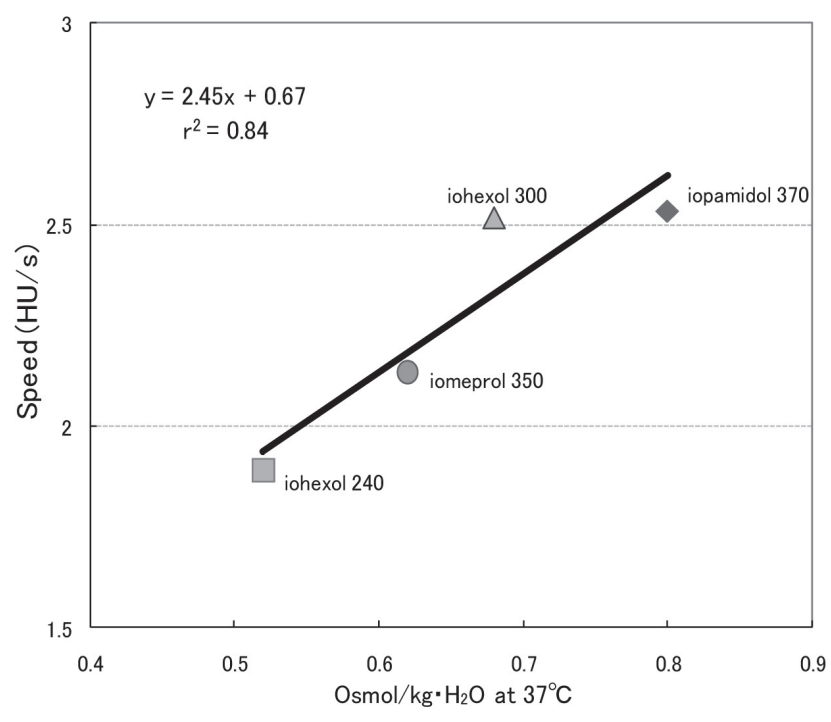

Fig. 11 Relations of the osmotic pressure $(\mathrm{Osmol} / \mathrm{kg})$ and the osmotic flow rate (HU/s).

考えられた。

一方，平衡相であるが，Itoh ら ${ }^{16)}$ は上腹部におけ る膵臓の質的診断検査において, 高齢者はCOおよ び血液量が減少しているため造影効果の低下を抑え ている，加えて，CO の低下は造影剤の排泄をより遅 延させ, 平衡相における造影効果の増強において有 利に働くと考察している。ささらに，山口ら ${ }^{17)}$ は肝臓の 質的診断検査において, 高齢の被検者群は腎機能の 低下によって，高齢者を除いた被検者群より平衡相 の造影効果が高いと考察している。これは排泄され るヨードの薬物動態が原因ということになる。した がって，血清クレアチニン $(\mathrm{Cr})$ 值が検査適応で，年 齢に差異がなければ影響は少ないと考え評価した。 そこで, 平衡相の AA およびIVCの造影効果という ことになるが, IVCにおいて Fig. 10 に示すように, 有意な差が認められたことから, 循環系の循環回路 から原因を考えた。循環回路すなわち血流路は器官 をセグメントとすると，いずれも動脈から細動脈 - 毛 細血管 - 細静脈 - 静脈の順序で，血流が分配されて いる，その分配比率は，セグメントにより異なるが, それぞれは直列につながっている，このため，細胞 外液の内部環境は動脈系と静脈系による二つの大き な容器で表すことができる。その容量は体重により異 なるが，静脈系は動脈系の 5 倍 ${ }^{18)}$ ほどある。そのた め, 浸透圧の影響を単位面積 $\left(\mathrm{cm}^{2}\right)$ 当たりの物理要因 で考えるとIVCにおいて有意差が生じてもおかしく ない，つまり，血液より浸透圧の高い造影剤 ${ }^{19)}$ が血管 内に大量に注入されると，血管外から血管内へ水分 が移行し，一過性に血漿量が増加すると考えられ る。また，動脈系の5 倍である静脈系は接触面積が 大きい分, 物質の交換効率も上昇すると推察でき 
る。しかし，造影剤のファーストパスにおける肺循環 においては一部造影剤の原液が循環している。ま た，動脈系にも濃度が高い造影剂が循環する。この とき副作用として熱感や稀に血管痛が発生する ${ }^{20)}$ 。こ れは注入速度 $(\mathrm{ml} / \mathrm{s})$ によって感じ方に違いはあるが, 高浸透圧性 ${ }^{21}$ が原因で細胞外液の平衡がとれないこ とによって起きている。また, 造影剤誘発性腎症 (radiocontrast-induced nephropathy; RCIN) も高浸透 圧性をリスク原因 ${ }^{22)}$ とする報告もあることから，浸透 現象による水分の移行速度は製剂によって違いがあ る.このことから, 動脈相と平衡相では造影剤の分布 容積 $\left(\mathrm{cm}^{3}\right)$ に違いがあるということになるが，この点に おいては接触および通過時間の影響が大きいと考えら れた。結果的に，有意な個体差はなく，肺循環および
上腹部の動脈相における造影剤のファーストパスは注 入時間程度 ${ }^{23)}$ と短いため, その影響は小さかったと考 えられる。

以上から, 造影剂の特性は平衡相を要する実質蔵 器系の検査において，造影効果に影響を及ぼす一因 子であるといえる.

\section{5. 結 語}

平衡相におけるIVCにおいてヨード使用量を一定 にしても，浸透圧值の違いにより造影能に差異を生じ させることが明らかになった。

検査目的に合わせ最適な造影検査を行うためには 造影製凨特性を理解することが必要である。

\section{参考文献}

1) Bae KT, Heiken JP, Brink JA. Aortic and hepatic peak enhancement at $\mathrm{CT}$ : effect of contrast medium injection rate-pharmacokinetic analysis and experimental porcine model. Radiology 1998; 206(2): 455-464.

2) Ono S, Akaizawa T, Gotou R, et al. Analysis of time-density curves of contrast media for improvement of chest dynamic incremental CT. J Comput Assist Tomogr 1999; 23(5): 753-757.

3) Kanematsu M, Goshima S, Kondo H, et al. Optimizing scan delays of fixed duration contrast injection in contrast-enhanced biphasic multidetector-row CT for the liver and the detection of hypervascular hepatocellular carcinoma. J Comput Assist Tomogr 2005; 29(2): 195-201.

4) Ueda K, Matsui O, Kawamori Y, et al. Hypervascular hepatocellular carcinoma: evaluation of hemodynamics with dynamic CT during hepatic arteriography. Radiology 1998; 206(1): 161-166.

5)八町 淳, 輪湖 正. 螺旋走查型 CTに扔ける最適造影 検査方法の検討. 日獨医報 1995; 40(2): 109-124.

6）井田義宏. 高体重患者へのヨード量設定- CT の X 線エ ネルギー変化と造影効果について．MDCT 至適造影法を 語る会第 4 回学術集会, 64 列(以上)の肝臓ダイナミック CT. 2010: 12-14.

7）辻岡勝美．腹部 CT に必要な基礎知識. Innervision 2010; 25(10): 5-9.

8) Awai K, Hatcho A, Nakayama Y, et al. Simulation of aortic peak enhancement on MDCT using a contrast material flow phantom: feasibility study. AJR Am J Roentgenol 2006; 186(2): 379-385.

9) 寺澤和晶. マルチスライス CT における肝臟領域の造影検 査法. Innervision 2010; 25(10): 10-15.

10) Kim MJ, Choi JY, Lim JS, et al. Optimal scan window for detection of hypervascular hepatocellular carcinomas during MDCT examination. AJR Am J Roentgenol 2006; 187(1): 198-206.

11）寺澤和晶. TDC から考える3D-CTAの造影法. Innervision 2008; 23(11): 25-29.
12) Gallotti A, Uggeri F, Favilla A, et al. The chemistry of iomeprol and physico-chemical properties of its aqueous solutions and pharmaceutical formulations. Eur J Radiol 1994; 18 (Suppl 1): S1-S12.

13）菊元力也. SDCT おけるルーチンワークの現状と工夫－洛 和会音羽病院の実際.アールティ 2003; 18: 11-14.

14) Corsico N. Topic pulmonary edema in the rat after intravenous injection of B 16880-comparison with iopamidol and iohexol. Progress in Medicine 1994; 14 (Suppl 1): 63-66.

15) 井田正博 監. X 線 CT 撮影における標準化「ガイドライン GuLACTIC」. 放射線医療技術学叢書 2010: 8-16.

16) Itoh $S$, Ikeda $M$, Satake $H$, et al. The effect of patient age on contrast enhancement during ct of the pancreatobiliary region. AJR Am J Roentgenol 2006; 187(2): 505-510.

17）山口 功, 森本 章, 庄賀一彦, 他. 造影剂増強効果に 影響を与える被検者因子および造影剤因子について。日 放技学誌 2002; 58(4): 517-523.

18) 本郷利憲, 廣重 力, 豊田順一 監. 標準生理学 第 6 版. 医学書院, 東京, 2005: 512-515.

19) Sakuma I, Sakuma K, Fukao M, et al. Effects of intravenously administered nonionic contrast media on circulating plasma volume-comparison between iomeprol and iopamidol. Progress in Medicine 1992; 12 (Suppl 1): 5-9.

20) Cipolla P, Tirone P, Luzzani F, et al. Pharmacodynamic effects of iomeprol for injection in experimental animals. Eur J Radiol 1994; 18 (Suppl 1): S32-S42.

21）曽我忠司, 前田正幸, 光森通英, 他. 非イオン性低浸透 圧造影剤による排泄性尿路造影一前処置としての水分制 限の必要性に関する臨床的検討一。臨床放射線 1989; 34: 233-236.

22) Pannu N, Wiebe N, Tonelli M. Prophylaxis strategies for contrast-induced nephropathy. JAMA 2006; 295(23): 2765-2779.

23）市川智章 編. CT 造影理論 第一版. 東京, 医学書院, 2004: 117-184. 


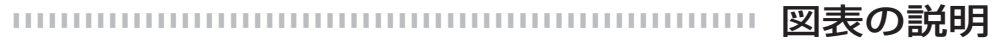

Fig. 1 各種製剤におけるヨード希勫量を一定にしたファントム

Fig. 2 浸透現象測定ファントム

Fig. 3 経過時間ごとの CT 画像

Fig. 4 腹部大動脈 (AA) 㧍よび下大静脈 (IVC)における CT 值の測定位置

Fig. 5 TDC ファントムに扔ける造影剤別上昇 CT 值の関係(ヨード使用量一定)

Fig. 6 ヨード希釈量を一定にしたファントムの CT 值 (air)

Fig. 7 浸透現象測定ファントムに扔ける経過時間 $(\mathrm{s})$ と最大 CT 值の関係

Fig. 8 経過時間 $(\mathrm{s})$ と浸透速度 $(\mathrm{HU} / \mathrm{s})$ の関係

Fig. 9 動脈相における腹部大動脈の上昇 $\mathrm{CT}$ 值 $(\mathrm{HU})$

Fig. 10 平衡相における腹部大動脈および下大静脈の上昇 $\mathrm{CT}$ 值 $(\mathrm{HU})$

Fig. 11 浸透圧 $(\mathrm{Osmol} / \mathrm{kg})$ と浸透速度 $(\mathrm{HU} / \mathrm{s})$ の関係

Table 1 各グループに扔ける被検者数および年齢と体重 (平均值 $\pm \mathrm{SD}$ )のデー夕

Table 2 各測定部位におけるグループごとの上昇 CT 值(平均值 $\pm \mathrm{SD}$ ) 